\title{
Ni convencionalismo ni naturalismo. La justificación epistemológica de la verdad en Donald Davidson*
}

\author{
Neither conventionalism nor naturalism. The epistemological justification \\ of the truth in Donald Davidson \\ JAIME DE Rosas AndReU** \\ Instituto de Filosofía, Pontificia Universidad Católica de Chile, Jiderosas@Uc.cl
}

Recibido El 30 de AGOSTo de 2020, APRoBAdo El 19 octubre 2020

\begin{abstract}
RESUMEN
En el presente trabajo me propongo defender la hipótesis según la cual la tesis davidsoniana del lenguaje, que presupone un conjunto de creencias y deseos compartidos, es un fenómeno cuasi-racional que proporciona las verdades $\mathrm{y}$, a partir de ellas, poder deducir otros pensamientos objetivos en el dominio de los valores. Desde ya adelanto que esta tesis se explica al entender que Davidson concibe que el pensamiento y el lenguaje son previos a la convención, por lo que, necesariamente, implica afirmar que comprende intrínsecamente al ser humano como un ser pensante, esto es, que goza de la inteligencia, de la capacidad de entender y comprender, aunque se encuentre desprovisto de contenido, es decir, negando un naturalismo o contenidos de creencias y deseos innatos.
\end{abstract}

\section{Palabras Clave}

Verdad, convencionalismo, naturalismo, Donald Davidson, racionalidad.

\begin{abstract}
In this paper I argue for the following hypotheses: The Davidsonian language thesis, which presupposes a set of beliefs and shared desires, is a quasi-rational phenomenon that weights the truths, and from them, is able to derive other objective thoughts in the domain of values. This view of Davidson conceives that thinking and language are prior to convention, and that necessarily implies the acknowledgement of humans as thinking beings; capable of understanding even when deprived of content, this is to say, negating naturalism or substance in beliefs and innate desires.
\end{abstract}

\section{KeY WordS}

Truth, conventionalism, naturalism, Donald Davidson, rationality.

\footnotetext{
* El presente artículo es una versión adaptada y reformulada de un capítulo de mi tesis para obtener el grado de Licenciatura en Filosofía en la Pontificia Universidad Católica de Chile. Agradezco los comentarios y el constante apoyo de Manuel Correia y Marcelo Diego Boeri; también quiero expresar mi agradecimiento a Gianinna Burlando por sus valiosas sugerencias a un primer borrador. ** (1) orcid.org/0000-0002-6884-1231 Google Scholar
} 
En el fundamento de la creencia bien fundamentada se encuentra la creencia sin fundamentos.

(Wittgenstein, Sobre la certeza, § 253.)

\section{Introducción}

Probablemente la pregunta filosófica más importante desde la Antigüedad hasta nuestros días sea: ¿Qué es la verdad? Es un viejo debate que no ha perdido actualidad ni ha escaseado en investigaciones y producciones científicas de diversas áreas (v.g.: psicología, biología, matemáticas, ciencias jurídicas). Sorprende la permanente renovación de los argumentos y el surgimiento de nuevas corrientes que innovan en los fundamentos epistémicos y elaboran nuevos sistemas filosóficos que incluso se oponen a las anteriores. Dentro de la epistemología contemporánea se halla la propuesta de Donald Davidson, quien se aparta desde un comienzo de la teoría de Ludwig Wittgenstein, consistiendo para este último la finalidad de la filosofía la tarea de sólo disolver errores y problemas lingüísticos (Investigaciones §133, 159); en cambio, para el filósofo norteamericano, se trata de identificar cómo construimos y atribuimos lo que entiende el otro. Así lo manifiesta el mismo Davidson: "En mi argumento lo esencial es la idea de un intérprete, alguien que comprende las emisiones de otro" (Subjetivo 166). Así, lo prioritario no radica en la noción de lenguaje y de la necesidad de interacción de un mismo lenguaje entre dos personas (Subjetivo 166), sino en la capacidad de interpretar y comprender lo que nos quiere decir nuestro otro interlocutor.

A lo largo de las páginas siguientes perfilaré con detalle la teoría semántica y epistemológica de Donald Davidson, explorando sus principales aportes a la teoría del conocimiento y a la filosofía de la mente. Mi análisis estará enfocado en destacar que la teoría davidsoniana no adhiere ni a una posición convencionalista ni naturalista; y se explica en virtud de la especial comprensión de la estructura del conocimiento humano a raíz de la elaboración de una teoría de la interpretación y teleológica de la acción. Se trata de un proyecto epistemológico que muestra que el sujeto nace desprovisto de conocimientos, pero que al entrar en contacto con el mundo es capaz de comunicarse prelingüísticamente, con prescindencia del lenguaje y de la convención. 


\section{La teoría semántica y epistemológica de Donald Davidson}

El programa semántico de Davidson no descansa en el significado de las palabras, más bien, consiste en una teoría de la interpretación que nos permita decodificar lo que nos quiere decir el otro. El éxito comunicativo no depende del modo convencional o del uso correcto del lenguaje, dado que cree que nos podemos dar a entender con prescindencia del significado de las palabras que se profieran, debido a que somos capaces de entender las intenciones de los hablantes, por ejemplo: en un texto, un determinado sujeto escribe "ratón", pero bajo el contexto en particular entendemos que se refiere a "patrón"; o cuando un niño pregunta o explica algo a otra persona, pero se expresa mal y la madre interviene para traducir lo que efectivamente quería decir su hijo. Esto, naturalmente, nos permite segregar y eliminar la mala práctica lingüística.

Por consiguiente, la propuesta davidsoniana, en vez de elaborar una teoría del significado, formula una teoría de la verdad, que, desde luego, la va a basar en la definición ofrecida por Alfred Tarski. Esta no es una teoría sintáctica de la verdad, es decir, que se defina en términos o lenguajes solamente gramaticales o formales (lógica proposicional o matemática). Al contrario, consiste en una teoría semántica porque se compone de una estructura tanto de nivel sintáctico como de carácter ontológico, "es decir, uno propiamente gramatical, en el que se determinan los objetos a que es aplicable el predicado 'es verdad', y otro en el que reciben interpretación esos objetos" (de Bustos 370-371). De esta manera, el proyecto davidsoniano es consciente de las deficiencias de una teoría semántica porque muchas de las oraciones no contienen condiciones de verdad, por ello, no responde qué es el significado, más bien se esfuerza en identificar las condiciones de confirmación de los significados, es decir, una comunicación exitosa consiste en el cumplimiento de las condiciones de verdad al estilo Tarski.

En suma, la empresa filosófica de Davidson interrelaciona la naturaleza de la acción humana y la naturaleza del significado lingüístico, intentando vincular intrínsecamente la mente (pensamiento, lenguaje, los estados mentales) y el mundo, a través de la comprensión de lo que hace posible nuestra capacidad para poder comunicarnos entre nosotros. De modo que, a riesgo de ser reiterativo, la teoría semántica de Davidson no descansa en un diccionario o manual de traducción, 
producción y conversión de ruidos a sonidos, sino que se centra en las acciones intencionales de los hablantes; por ello es una conexión de la semántica con las acciones de los agentes.

Entonces, el rendimiento explicativo de los significados de las oraciones se da recurriendo o constatando sus condiciones de verdad. Para saber sobre las creencias y deseos no se tiene que saber lo que significan las palabras, pues se requiere de las circunstancias especiales en las que se profieren las palabras (Davidson, De la verdad 170), esto es el contenido proposicional de carácter materialista y ontológico, por ello es que hay una interrelación entre la teoría de la acción con la interpretación. Puestas así las cosas, nos encontramos frente al corazón del programa teórico de Davidson: el principio de caridad. Este principio atiende a entender las intenciones de los agentes, de modo tal que abarca la atribución de racionalidad, la capacidad de lenguaje y de pensamiento entre los intérpretes. Asimismo, lo manifestaba el discípulo de Quine:

afirmaremos ahora que hablar una lengua no depende de que dos o más hablantes hablen de la misma manera; solamente requiere que cada hablante se haga intencionalmente interpretable al otro (el hablante debe 'seguir' más o menos como el otro espera, o al menos como esté equipado para interpretarlo. Ésta es ciertamente una condición necesaria para la comunicación exitosa. (Davidson, Subjetivo 167)

El fin de la interpretación no es el acuerdo sino la comprensión. Mi punto de vista siempre ha sido que la comprensión sólo puede asegurarse interpretando en una forma que la lleve hacia el tipo correcto de acuerdo. (Davidson, Subjetivo 20-21)

Estas citas son sobradamente demostrativas de la peculiar importancia del principio de caridad, cuya función principal es identificar la naturaleza de las creencias y de la verdad con el fin de la búsqueda de la certeza y su crítica al escepticismo; y secundariamente, ayuda a disolver los problemas de los desacuerdos y malentendidos entre el intérprete y el hablante. Es un dispositivo que intenta explicar cómo proceder en un proceso hermenéutico, debiendo primero saber y luego ayudar a la resolución de los desacuerdos. Davidson aclara que este principio se compone de otros dos principios: i) principio de coherencia: que consiste en interpretar la consistencia lógica en el pensamiento de 
los hablantes; y ii) principio de correspondencia: los hablantes responden a los mismos rasgos que dan cuenta del mundo compartido entre ellos. Con ellos, este principio de caridad nos permite lograr superar los problemas de significado y creencias al maximizar la racionalidad de lo que nos quiere decir el otro, tomando como base que todos los hablantes gozan de una racionalidad lógica y con creencias verdaderas respecto del mundo (Davidson, Subjetivo 288).

En este sentido, se trata de una teoría de la verdad que nos revela y facilita nuestra interacción social. En efecto, los principios de racionalidad y de caridad -al ser una teoría eminentemente de la acción y de la interpretación- dan cuenta de la constitución de una teoría de la razón teórica y práctica. Encontramos la aplicabilidad de una "filosofía práctica" que plantea, en un nivel básico, las condiciones mínimas y necesarias que posibilitan la inteligibilidad entre los agentes. Entre estas condiciones, según Davidson, está la capacidad de maximizar la verdad entre los hablantes a través de la simple confrontación en el mundo, de modo tal que nos permite explicar la intención y la acción de los intérpretes. Resulta pertinente destacar que para Davidson el pensamiento es previo al lenguaje, puesto que una criatura no puede tener pensamientos a menos que sea intérprete del habla de otro (De la verdad 166). Así, el pensamiento o las actitudes proposicionales son dados previamente al sujeto (y no reducidos al lenguaje), porque el hombre goza de una inteligencia para poder identificar y discriminar unas creencias respecto de otras (Subjetivo 142). Sin más, la visión esencial de Davidson acerca del ser humano -y que lo diferencia de los animales- es que por naturaleza los humanos nacen con la facultad o capacidad de pensar, esto no significa que vengan con contenido, conocimientos o virtudes, sino con la capacidad de entender y comprender, con la facultad de la inteligencia para poder ser capaces de interpretar a los otros.

Más concretamente, se trata de un fenómeno prelingüístico en el que los actores son capaces de captar y distinguir lo que es verdadero y lo que es falso al atribuir deseos, creencias y pensamientos que posean los otros interlocutores. De modo que los hablantes pueden, con confianza, interpretar qué nos quiere decir el otro con prescindencia de los recursos lingüísticos. Muy instructivo son los ejemplos de Davidson:

Un hombre que toma una manzana y no una pera cuando se le ofrecen ambas puede estar expresando una preferencia 
por lo que está a su izquierda y no a su derecha, por lo que es rojo y no amarillo, por lo que ha visto primero, o juzgado más costoso". (De la verdad 171)

Si vemos a un hombre tirando de ambos extremos de un trozo de cuerda, podemos decidir que está luchando consigo mismo, que quiere mover la cuerda en direcciones incompatibles... No surge ningún problema si la explicación es que él quiere cortar la cuerda. (De la verdad 168)

Lo que ocurre es que, según demuestra Davidson, podemos atribuir pensamientos a las conductas de otras personas en virtud del conocimiento de las circunstancias bajo las cuales se está interpretando. Pero, recordemos que esta interpretación se realiza conforme a la coherencia, es decir, de acuerdo con un patrón de comportamientos que constituye una base evidencial para imputar creencias y deseos; la teoría davidsoniana interrelaciona una teoría de la interpretación junto a una teoría teleológica de la acción para poder inferir y revelar la verdad de los hablantes. En efecto, el principio de caridad y de racionalidad en Davidson son principios intuitivos, de carácter biológico, que dan cuenta de una racionalidad que orienta la praxis, otorgando la capacidad de relacionarnos. Esto implica la capacidad para formular juicios de valor, pero como el lenguaje y el pensamiento son previos a la convención, entonces se trata de una racionalidad desprovista de razones políticas, ideológicas o religiosas.

La idea de Davidson es afirmar que la convención es un fenómeno posible si, y sólo si, hay sujetos racionales en posesión del lenguaje y del pensamiento. Teniendo en cuenta esta estructura racional, es que resulta inadmisible describir la teoría davidsoniana como una tesis "anticonvencionalista", como sostiene Eduardo Fermandois (129-146). Si bien reconoce que Davidson no es un opositor de las reglas o convenciones y que el planteamiento davidsoniano no cree necesario recurrir a un determinado uso estándar de comunicación, considera que "lo único importante es que el hablante ponga a disposición de su interlocutor las pistas suficientes, de modo que éste pueda captar lo que se le intenta decir. Esta exigencia mínima representa la condición necesaria" (140). Frente a esto, Fermandois critica que Davidson, al intentar eliminar la idea del uso compartido del lenguaje, no ofrece criterio alguno que nos permita pensar en 
una normatividad del lenguaje (142). Es oportuno detenerse aquí para revisar por qué esta crítica es inviable.

En primer lugar, el principio de caridad no es un dispositivo que nos permita resolver casos difíciles: desambiguar todos los conceptos vagos e indeterminados; más bien es una herramienta que nos garantiza un piso mínimo de entendimiento entre los interlocutores. Se trata de un principio no arbitrario, de carácter biológico e intuitivo, para interpretar correctamente qué nos quiere decir el otro en virtud de las creencias, deseos y apetitos que son intrínsecos al ser humano (Davidson, Problems 67). Sin embargo, bajo este contexto, Fermandois lleva cierta razón en lo siguiente: el modelo davidsoniano presenta un enfoque insuficiente al plantear el "primer significado" (first meaning) para captar una determinada intención de un hablante de una cierta manera, de modo que el no respeto a las reglas de los usos lingüísticos no permitirá comunicarnos exitosamente. Ciertamente, Davidson cree que "bajo condiciones óptimas para la comunicación, podemos finalmente eliminar [el conocimiento de las convenciones del lenguaje], y en teoría podríamos haber eliminado desde un principio" (De la verdad 275). En este punto, creo que Fermandois acierta parcialmente, dado que la teoría de Davidson no satisface poder detectar la intención de los hablantes en diálogos sofisticados o de conversaciones complejas (v.g.: discusiones filosóficas o conocimiento científico o técnico). No obstante, la propuesta davidsoniana, en esencia, no pretende ofrecer una pauta exhaustiva de interpretación para cada hablante y situación particular (De la verdad 275), sino que únicamente nos indica el esqueleto general de la interpretación, que está compuesto por los principios de coherencia, correspondencia y por los objetos del mundo (denominado "modelo de la triangulación", lo veremos en los párrafos siguientes).

Davidson no cree que accedamos directamente a los estados mentales (con respecto a la interpretación de los interlocutores con arreglo al principio de caridad). Por eso, es partidario de un externalismo mental; sin embargo, junto con el modelo de la triangulación -que consiste básicamente en el conocimiento de las circunstancias bajo las cuales alguien considera que ciertas oraciones son verdaderas- componen los criterios normativos que nos permiten pensar el lenguaje y las convenciones. Vemos así que, en virtud del principio de caridad y del modelo de la triangulación, podemos comunicarnos elementalmente $y$, así, coordinarnos socialmente en cuestiones básicas, como, por ejemplo: 
al ver un auto nuevo, de última generación, estacionado en el centro de la ciudad, nadie en su sano juicio creerá que se trata de un auto abandonado y que pueda reclamarlo de dominio suyo.

Ahora queda relativamente claro que Davidson sí ofrece criterios normativos para pensar la normatividad del lenguaje y que el principio de caridad responde a capturar la intención de los hablantes a un nivel no sofisticado de conversaciones y en una etapa previa a la convención y al lenguaje. Por lo mismo, se trata de interpretaciones desprovistas de juicios de valor y de comparaciones intersubjetivas. Con relación a la tesis anticonvencionalista, es necesario seguir desmintiéndola, ya que, por otro lado, no debe aseverarse con el prefijo "anti" porque eso significa imputar a Davidson ser un filósofo que se dedica a remover y a destruir el modo convencional para comunicarnos. Es verdad que en Communication and Convention cuestiona la regularidad de las reglas y de las convenciones como garantías de comunicación, porque cree firmemente que no es el corazón de la comunicación lingüística (Davidson, De la verdad 273-274). Sin embargo, en los siguientes párrafos del texto, parece comprometerse con la idea de la convención por su utilidad práctica: "Vemos así que el conocimiento de las convenciones del lenguaje constituye un punto de apoyo práctico para la interpretación, sin el cual no podemos pasárnoslas en la práctica" (De la verdad 274). En este pasaje se ve que Davidson, a pesar de ser un crítico del convencionalismo, sí es un partidario de la posición de seguir una regla, simplemente por ser una herramienta que nos facilita entendernos recíprocamente. Por ende, es un error encasillarlo como un anticonvencionalista; más bien, es un no convencionalista. En suma, con estos antecedentes vemos que cobra más sentido su tesis de que el lenguaje y el pensamiento son una condición para tener convenciones.

Llegados a este punto es que podemos atribuir que el programa teórico de la verdad de Donald Davidson, que presupone un conjunto de creencias y deseos compartidos, es un fenómeno cuasi-racional, dado que Davidson antes de proceder al convencionalismo interpreta al sujeto como un ser pensante que, intrínsecamente, está dotado con la capacidad de inteligencia, que permite a los intérpretes entender y comprender a los hablantes. Luego, a través del lenguaje y del modelo de la triangulación que él mismo ofrece, los sujetos van nombrando los rasgos y cosas del mundo. Recordemos que para Davidson el pensamiento se constata o aparece en la triangulación, esto es: en la 
relación entre los agentes y el entorno al cual reaccionan mutuamente para darse el pensamiento. Por ello, se puede afirmar que Davidson concibe que el pensamiento y el lenguaje son a priori y en la vida en comunidad se va completando y nombrando las palabras del lenguaje. Por lo tanto, la teoría davidsoniana versa sobre una concepción realista de la verdad (Subjetivo 194) y prescinde de la confrontación al mundo exterior.

Si lo que distingue a la especie humana del resto de las especies del reino animal y de los seres vivos es el pensamiento, y si este únicamente se da por medio de la interacción social, entonces estamos frente a una comprensión aristotélica del hombre: si nos aislamos de la sociedad nos volvemos bestiales, pero en sociedad nos perfeccionamos. En este horizonte se pronuncia Davidson:

\begin{abstract}
Poseemos la idea de creencia solamente a partir del rol de la creencia en la interpretación del lenguaje, pues como actitud privada ella no es inteligible excepto como ajuste a la norma pública provista por el lenguaje. De allí se desprende que una creatura debe ser miembro de una comunidad de habla si es que va a poseer el concepto de creencia. $Y$ dada la dependencia de otras actitudes respecto de la creencia, podemos decir, generalizando, que sólo una creatura que pueda interpretar el habla puede poseer el concepto de un pensamiento. (Subjetivo 178)
\end{abstract}

La tesis que enseguida interesa, se construye a partir de un precepto metodológico que desarrolla en Communication and Convention (1982), y que tiene como base que el lenguaje es previo a la convención, pese a que se reconoce la utilidad y necesidad de "seguir" el lenguaje como una regla: "La verdad indica más bien que el lenguaje es una condición para tener convenciones" (De la verdad 276). En virtud de esta cita, se desprende claramente que no puede decirse que Davidson es un convencionalista, porque el origen de la convención es posible solo después de la racionalidad del intérprete. El punto de partida es que el lenguaje es un fenómeno social que únicamente puede ser comprendido desde una esfera pública o intersubjetiva, como la denomina el propio Davidson (Subjetivo 154). El autor en cuestión reconoce que toda interpretación apunta a una dimensión objetiva, pero ¿cómo sabremos con seguridad cuáles creencias son verdades y cuáles son falsas? ¿Qué nos asegura que efectivamente estamos ante verdades absolutas? 
Aunque un pensamiento sea individual, en The Second Person (1992), el autor nos señala que su contenido no deja de ser público y esto se explica a partir del modelo de la "triangulación" que ofrece Davidson. Consiste básicamente en que para que haya un pensamiento debe haber, al menos, dos personas y un objeto en cuestión. De este modo, ambas personas y el objeto componen un vértice oángulo cada uno. Así, la triangulación permite explicar la objetividad del pensamiento y el contenido empírico de los pensamientos del mundo. La triangulación es la explicación de cómo la experiencia dota de un contenido específico a nuestros pensamientos, pues este modelo geométrico es nuestro aprendizaje de carácter inductivo, cuyo fundamento está enraizado en conexiones históricas directas y compartidas socialmente. En concreto, en el cuadro teórico davidsoniano, existe una argumentación que se aparta tajantemente de la concepción cartesiana del cogito ergo sum y del omnibus dubitandum est (dudar de todo), porque rechaza la idea del autoconocimiento y de un conocimiento nómico (De la verdad 156). Además, pone de manifiesto un externalismo mental al entender que el pensamiento o las actitudes proposicionales pueden conocerse y explicarse solamente desde el punto de vista colectivo. Así, el ejercicio hermenéutico es realizado, principalmente, desde la perspectiva de la tercera y la segunda persona. Sin embargo, no rechaza la autoridad de la primera persona dado que se encuentra presente en todas las creencias; no obstante su pensamiento individual, su contenido es esencialmente público, por ello se trata de una tesis de holismo mental (Subjetivo 26).

En efecto, ante el fenómeno de la triangulación -en realidad en ese momento de confrontación y no antes-, se constata que los intérpretes están en posesión de la racionalidad porque los estados mentales, el pensamiento o también llamadas actitudes proposicionales -términos unívocos en el sentido de estado psicológico para Davidson- no pueden existir si no se vive en sociedad. La tesis clave y decisiva para nuestro autor es que la condición necesaria para la aparición del pensamiento en una mente es únicamente en la interacción con otras criaturas pensantes. En palabras de Davidson: "antes de que cualquiera pueda tener pensamientos, ha de haber otras criaturas (una o más) que interactúen con el hablante" (Mente 160). Así, el lenguaje y el pensamiento se dan cooriginariamente y previo a la convención, porque el hombre es una criatura social, que se desarrolla y se perfecciona en compañía. 
Esta propuesta de Davidson, de entender la verdad como una cuestión pública o, dicho de otro modo, que el pensamiento aparece en la interacción social y no antes, coincide con Wittgenstein al negar el lenguaje privado (Davidson, Subjetivo 170). Para el filósofo austriaco, el lenguaje -por definición- requiere de otros interlocutores. Desde este punto de vista, Davidson está siguiendo a Aristóteles, al negar que el hombre nazca con ciertas virtudes naturales o un innatismo de ellas. Así creía el Estagirita al manifestarlo en el capítulo XIII del Libro VI de la Ética a Nicómaco: "Pues también en los niños y los animales se dan los hábitos naturales, pero sin la razón son manifiestamente dañinos" (1144b8-10). Este pasaje ha sido interpretado como una expresión de naturalismo restringido en Aristóteles, sin embargo, no debe olvidarse que "ninguna virtud del carácter surge en nosotros naturalmente sino por una cierta habituación... Las virtudes intelectuales, en cambio, surgen y crecen a partir de la enseñanza, y por eso requieren de experiencia y tiempo" (Boeri 173). Más concretamente, el discípulo de Platón concibe que por el mero hecho de ser natural no significa que siempre sea bueno porque no están acompañadas del noûs, pues, aunque algunos niños desde el nacimiento exhiban rasgos de valentía o moderación, en términos estrictos no son virtudes, dado que por definición se exige la capacidad de deliberación (proáiresis), cuya facultad y etapa intelectual aún no ha sido desarrollada. Por lo tanto, puede interpretarse que en vez de "virtud" se refiere a "talento" o "perspicacia".

Bajo esta misma línea de comprensión, Davidson afirma, al igual que Wittgenstein, que los niños obtienen el conocimiento al ser aprendido por medio de la definición ostensiva, aunque advierte su insuficiencia y admite más vías de adquisición primaria del lenguaje (Truth 258259), tales como el adiestramiento ostensivo, el fenómeno de la generalización y el de la similaridad percibida (Mente 157). A juicio de Davidson, estas vías de adquisición primaria del lenguaje son dadas gracias a los mecanismos selectivos congénitos de la anatomía humana, propios de la constitución de la mente, que permite la adquisición del conocimiento a través de la triangulación; lo designa: estímulo natural.

Esta es la explicación que nos permite evidenciar el conocimiento objetivo. De este modo, la objetividad se halla en las muy parecidas o mismas respuestas de los hablantes y de los intérpretes. La 
reacción a este elemento congénito de la mente humana es lo que provoca respuestas innatas, es la condición esencial que permite a los interlocutores entrar en la posesión del concepto de verdad objetiva (Davidson, Mente 160-161). Si esta lectura davidsoniana es correcta, es decir, si los mecanismos selectivos congénitos son inherentes a la mente humana y sus respuestas innatas son de carácter social al ser las (casi) mismas respuestas, entonces ésta es la condición esencial del pensamiento humano, lo que equivale a denominar una comprensión cuasi-racional de la especie humana. De esta manera, Davidson cree que en lo mental hay un cierto tipo de fenómeno biológico que puede apreciarse en la interacción de los niños al aprender nuevas palabras, habiendo al menos dos criaturas que dan respuestas innatas, en virtud de estos estímulos. De ahí que pueda predicarse que en el cuadro teórico de Davidson se halla una tesis de una estructura singular de tabula rasa que determina parcialmente los caracteres y conocimiento de los hablantes, que posibilita y conduce hacia la posesión compartida del concepto de verdad intersubjetiva u objetiva (Mente 160-161).

\section{El diálogo socrático: como garantía y estructura de control de la verdad}

En el horizonte de la teoría davidsoniana, el lenguaje -que es una etapa posterior al estadio de la cuasi-racionalidad-constituye un principio de racionalidad compartida que permite explicar la objetividad. Como indiqué antes, en Davidson se halla la tesis de una comprensión cuasi-racional de la especie humana: nacemos sin conocimientos, pero en el contacto con el mundo (modelo de la triangulación) nos permite relacionarnos con otros de manera prelingüística sin tener la necesidad de atarnos a una experiencia de convención sobre el conocimiento para poder entendernos. En esta medida, es un proyecto originariamente antimetafísico que postula desde ya la verdad como idea inherentemente social; rechazando que los pensamientos tengan un origen consensual. Los pensamientos, como las verdades absolutas, son inherentes al mundo público común; así, la propia posibilidad del pensamiento exige normas compartidas.

Con ocasión de la entrega del Premio Hegel, concedido en 1991 por la ciudad de Stuttgart, Davidson dicta la charla Dialektik und Dialog. Ya en presencia de una etapa madura de su razonamiento filosófico, intenta demostrar la afirmación del desarrollo y alcance de la verdad objetiva 
a través del lenguaje compartido, más específicamente a través del diálogo socrático, a raíz del diálogo Filebo de Platón. Aquí, Davidson señala que en el Filebo hay un retorno al "método elénctico", propio de sus obras tempranas (Truth 252). Este es un método refutatorio que da cuenta que el otro en realidad no sabe bien lo que pretende saber; está pensando, más bien, para decepcionar al otro, que para alcanzar la verdad. De hecho, Hegel afirma que en el estilo socrático existe un "propósito de llevar al interlocutor a concesiones que encerrasen el punto de vista opuesto al que les había servido de punto de partida" (58). A esta metodología Davidson la denomina una dialéctica inconclusa, porque no se garantiza haber alcanzado la verdad objetiva (Truth 253). Este método elénctico goza, según Davidson, de la siguiente estructura:

i) está compuesto por un interrogador y un interrogado;

ii) se plantea una pregunta portentosa: ¿qué es la justicia? ¿qué es el conocimiento? ¿qué es la virtud?;

iii) al responderse, se intenta demostrar al interlocutor su incoherencia con otras cosas que él cree;

iv) el interlocutor intenta enmendar su respuesta con otras cosas que cree.

Entonces, es un método que pretende una consistencia/coherencia al ir eliminando las inconsistencias lógicas, de tal modo que esta teoría de la coherencia nos permite asegurar que lo que queda es un cuerpo de verdades no ocultadas. El objetivo de este método socrático es capturar y revelar el bien o lo bueno, que es lo objetivo, absoluto, necesario y universal en las relaciones entre los hombres y de estos con la naturaleza (Hegel 51).

Por su parte, Davidson reconoce que esta idea la recoge de Vlastos, de una lógica de la refutación que nos ayuda a resolver las inconsistencias (Truth 242). En efecto, nos permite identificar nuestras creencias erróneas al ir eliminando las contradicciones $y$, de este modo, vamos progresando en el diálogo. Es una metodología de descarte, por lo tanto, no nos asegura que las demás creencias sean verdaderas. Así, Davidson cree que avanzando en esta línea metodológica se nos permitirá dispersar los conceptos que empleamos, dando cuenta que necesitamos conceptos mejores o diferentes. Paralelamente, en Three Varieties of Knowledge (1991), Davidson concluye, de la siguiente manera, su reflexión acerca la imposibilidad del pensamiento individual y de lo inevitable del aspecto objetivo de todo pensamiento: "Lo que es seguro es que la claridad y 
efectividad de nuestros conceptos crece con el desarrollo de nuestra comprensión de los demás. No existen límites definidos respecto a lo lejos que puede llevarnos o nos llevará el diálogo" (Subjetivo 299).

Ahora bien, conviene recordar que su criterio normativo es que el entendimiento entre los interlocutores, a través de la triangulación, es conforme al criterio de verdad al estilo de Tarski, en el que se satisface una adecuación material y una corrección formal (de Bustos 371-373); y el argumento central es que las criaturas racionales poseen la habilidad de intuición comunicativa, esto es, la inteligencia de poder comprender qué nos quiere decir el otro. Por lo tanto, en el desarrollo del diálogo socrático, al compartir las criaturas racionales las mismas condiciones del pensamiento y verificarse las similares respuestas innatas y cimentar las bases del pensamiento bajo un acervo del conocimiento, arrastra, según Davidson, que la mayoría de las creencias sobre el mundo sean verdaderas. De esta manera se convierte en una metodología que contiene componentes deontológicos y cuantificadores universales que ayudan a evitar que fracase, en medio del diálogo, este modelo de constante práctica argumentativa. Así, las personas al interrelacionarse, y ser el pensamiento o las actitudes proposicionales de carácter social, se deriva que al comunicarse entran en posesión de la verdad objetiva; algo así como que al entrar en contacto con el mundo evidenciamos que pagar la cuenta de luz dos veces es injusto y nadie en su sano juicio podría afirmar lo contrario.

Así las cosas, hemos visto el modo en que las condiciones necesarias para la configuración y el comienzo del diálogo socrático, en Davidson, son tanto la ontología (en especial el lenguaje), la lógica y la dialéctica, cuyos elementos esenciales posibilitan el alcance de la verdad objetiva. La convicción socrática es que lo bueno se encuentra en la naturaleza misma del espíritu, pero para extraer lo interior del hombre éste debe realizarse en el exterior, de este modo el conocimiento de la identidad del sujeto está vinculado directamente con la realidad del mundo. Davidson rescata de Sócrates la emergencia y desarrollo de la racionalidad, cuyo origen está dentro del sujeto mismo, que la racionalidad es intrínseca al ser humano; y los principios lógicos y morales no son mera convencionalidad ni naturalismo, sino que es ontológicamente factual, de modo que lo bueno o lo objetivo se haya en nuestra conciencia individual; ella dará cuenta que los principios 
falsos se destruyen por sí mismos. Davidson recupera de Sócrates que, en virtud de la consumación del espíritu subjetivo, el hombre se posiciona como un ente pensante que necesita del otro y que se manifiesta en el diálogo socrático: aquí el individuo excavará en su propia conciencia y encontrará el conocimiento de los principios y máximas morales. Con palabras de Hegel, justamente éste es el gran aporte de Sócrates a la humanidad: "En efecto, el eje de toda la conversión histórico-universal que forma el principio de Sócrates consiste en haber sustituido el oráculo por el testimonio del espíritu del individuo y en hacer que el sujeto tome sobre sus hombros la decisión" (78).

Pero lo más importante de todo es que la propuesta davidsoniana, en conexión con la refutación dialéctica socrática, ofrece los principios de racionalidad y de caridad como dispositivos que garantizan el proceder de un proceso hermenéutico, en el que nos podemos dar a entender a pesar de las fallas lógicas y lingüísticas. Esto es de vital importancia en la estrategia argumentativa de Davidson, puesto que es de la idea de que no toda dialéctica en su inicio está conducida por la lógica, de ahí que parte de la racionalidad puede verse impulsada por deseos egoístas que resulten contraproducentes, pero lo importante es que en el camino dialéctico vamos descubriendo los principios lógicos. Si se tiene en cuenta este detalle, la interpretación que Davidson hace de Sócrates a través de Vlastos abre un campo medio entre el naturalismo de las leyes morales y el solo convencionalismo, pues se garantiza la racionalidad del diálogo y de la acción por medio de principios anteriores que no son innatos, sino que son producto de la conciencia misma del sujeto en su reconocimiento y continuación del diálogo.

Los interlocutores fluyen en el diálogo en virtud del reconocimiento de lo que dice el otro. Así, en el diálogo socrático los hablantes encuentran principios lógicos universales que funcionan como sistema de control de la estructura dialéctica. De este modo, la racionalidad que emana de la tesis davidsoniana parte con los principios biológicos de racionalidad y de caridad que nos permite entendernos sin necesidad de crear reglas para ello, y luego, en la entrada al método elenctico socrático, vamos formando y desarrollando nuestro razonamiento, en ella vamos aprehendiendo y derivando los principios lógicos universales que nos contendrá y garantizará la racionalidad de la discusión dialéctica, salvaguardándonos de verse tambaleadas gracias a las verdades encontradas por estas vías refutatorias de la argumentación. De ahí 
que la dialéctica socrática no sea más que otra vía argumentativa que refuerza su teoría de la coherencia por ser intrínsecamente consistente y racional.

\section{Conclusión}

En suma, asistimos en la triangulación al fenómeno cuasi-racional porque incluso en nuestra interacción social primitiva aparece el pensamiento; el lenguaje no es una convención, es decir, no es una regla producto de un acuerdo o consenso, sino que, dado el hecho de la existencia de la relación de agentes y un entorno que con el que se relacionan mutuamente, se configura de facto el pensamiento. En otras palabras, el ser humano posee pensamientos desde un comienzo, se compone de creencias y deseos, pues el hablante debe tener el concepto de conveniencia para saber qué es lo que le conviene para celebrar, por ejemplo, un trueque. En efecto, para explicar el comportamiento lingüístico no puede recurrirse a los conceptos de convención o reglas.

La crítica anticartesiana de Davidson, quien no agota sus argumentos en el externalismo mental, sino que también arguye un carácter antirepresentacionalista en razón de quela adquisición del conocimiento a raíz de la triangulación no se teje en una dimensión personal, sino que puede darse únicamente en la intersubjetividad. La triangulación da cuenta de la normatividad interpersonal, dándose solamente en ese plano el significado del conocimiento y de las actitudes proposicionales, no pudiendo sus contenidos ser independientes de los objetos y elementos fácticos a los que se refieren (Navia 78). Así, lo que resulta epistemológicamente relevante de la crítica al representacionismo, que se encuentra dominado esencialmente en las filosofías cartesianas, es que debemos considerar que el sujeto nace sin predicados, es un concepto vacío, pero que en contacto con el mundo y en el camino lo vamos descubriendo y atribuyendo cualidades y ahí esos predicados van contribuyendo al contenido de ellos.

El modelo de la triangulación de Davidson, según la interpretación de que la certeza debe estar en la realidad efectiva y no en la pura intuición e individualidad de la conciencia, junto a los insumos de los principios de caridad y de racionalidad, nos permiten atribuir pensamientos a las conductas de otras personas en virtud del conocimiento de las circunstancias bajo las cuales se está interpretando. Se trata de una 
propuesta epistémica que interrelaciona una teoría de la interpretación junto a una teoría teleológica de la acción para poder inferir y revelar la verdad de los hablantes.

El proyecto epistemológico de Davidson muestra que el sujeto no nace completamente ignorante dado que en el contacto con la realidad y con los otros se determinan verdades y falsedades que permiten, desde luego, poder comunicarnos con prescindencia del lenguaje y de acuerdos expresos. A partir de ello, no puede encasillarse a Davidson ni como un "convencionalista" ni como un "naturalista". Si lo que he argumentado es razonable, espero haber mostrado que la propuesta davidsoniana trata de una comunicación prelingüística en la que podemos atribuir pensamientos, creencias y deseos desprovista de razones políticas, ideológicas o religiosas. Es una filosofía que pretende mostrar que el humano goza de la inteligencia para distinguir lo verdadero y lo falso con prescindencia -y en una etapa previa e incluso posterior- del lenguaje y de la convención.

Por otro lado, al articular los diferentes tipos de argumentaciones contenidas en la embestida davidsoniana, entre ellas la tesis anticartesiana, antirepresentacionalista y el hecho de que Davidson analice las condiciones de verdad de cada ítem, lo deja claramente en una posición incompatible con la doctrina fundacionista. La propuesta davidsoniana va a escapar de la epistemología tradicional y elaborará novedosamente una teoría que denominará "Monismo anómalo". Esta es una alternativa filosófica interesante pero que no ha estado exenta de críticas, tales como un supuesto abandono del fundacionismo metafísico (Navia 85); la carencia de una fuerza modal que apoye algún tipo contrafáctico acerca de su relación de sobreveniencia (Liz 222); una tesis que tiende a convertirse en un epifenomenismo con causales inertes (Moya 239-269), entre otras. Lo que sí es claro es que versa sobre una propuesta de las acciones intencionales que viene a remarcar el holismo mental que intenta defender Davidson.

Concluyo: el principio de racionalidad que surge a raíz del fenómeno cuasi-racional es de carácter biológico, por lo que la adquisición inductiva de los pensamientos se compone de un catálogo contundente de creencias verdaderas, porque Davidson asume que en el lenguaje hay una preponderancia de creencias verdaderas por sobre las falsas, de modo tal que la interpretación asume a priori la 
posibilidad de descartar un error gramatical. Esta comprensión permite, desde luego, concebir las verdades objetivas. Estas verdades, al ser un cúmulo consistente de creencias verdaderas, nos permiten destruir y eliminar creencias falsas. Lo que nos otorga el programa davidsoniano es una concepción coherentista de la verdad, al entender al sujeto activo mentalmente y a través de un patrón de creencias verdaderas, es decir, a través de una inferencia inductiva vamos confeccionando las verdades objetivas. La tesis davidsoniana trata de una cuasi-racionalidad ya que el sujeto va adecuándose como sujeto racional, porque no se trata de un modelo enteramente racional ni tampoco desprovisto de creencias; en tanto el sujeto goza de una cuasi-racionalidad, que, si bien no tiene un pensamiento innato, pero es evidente para todos al entrar en contacto en comunidad.

\section{REFERENCIAS}

Aristóteles. Ética a Nicómaco. Introducción, traducción y notas de José Luis Calvo Martínez. Alianza Editorial, 2007.

Boeri, Marcelo. Apariencia y realidad en el pensamiento griego. Colihue, 2007.

Davidson, Donald. Mente, mundo y acción. Ediciones Paidós. 1992.

---. De la verdad y de la interpretación. Gedisa, 2001.

---. Subjetivo, Intersubjetivo, Objetivo. Cátedra, 2003.

---. Truth, Language, and History. Oxford University Press, 2005.

---. Problems of Rationality. Oxford University Press, 2005.

De Bustos Guadaño, Eduardo. Filosofía del Lenguaje. Librería UNED, 1999.

Fermandois, Eduardo. “¿Comunicación sin lenguaje? Sobre reglas, lenguajes y la filosofía tardía de Davidson". Ontologia, Conhecimento e Linguagem, compilado por Ulysses Pinheiro, Marco Ruffino y Plinio Smith Junqueira, MAUAD Editora Ltda, 2001, pp. 129-146.

Hegel, Georg Wilhelm Friedrich. Lecciones de historia de la filosofía. Fondo de Cultura Económica, 1995. 
Liz, Antonio Manuel. "Causalidad y contenido mental". La mente humana, editado por Fernando Broncano, Trotta, 2007, pp. 207-244.

Moya, Carlos. "Davidson y la eficacia causal de la mente". Ensayos sobre Davidson editado por Carlos E. Caorsi, Fundación de Cultura Universitaria, 1999, pp. 239-269.

Navia, Ricardo. El argumento antiescéptico de Davidson como punto de convergencia de innovaciones radicales. Areté, Vol. 22, num. 1, mar. 2010, pp. 69-85. http://revistas.pucp.edu.pe/index. $\mathrm{php} /$ arete/article/view/586

Wittgenstein, Ludwig. Investigaciones filosóficas. UNAM, Crítica, 1988. ---. Sobre la certeza. Gedisa, 1988. 